\title{
Comparative Evaluation of the Retentive Qualities of Three Different Post Systems Used for Endodontically Treated Teeth for Providing Restoration - An in Vitro Study
}

\author{
Shraddha Ramteke ${ }^{1}$, Seema Kambala², Surekha Godbole ${ }^{3}$, Anjali Borle ${ }^{4}$, Tanvi Jaiswal ${ }^{5}$ \\ ${ }^{1}$ Department of Prosthodontics, SPDC, Sawangi (M), Wardha, Maharashtra, India. ${ }^{2}$ Department of Prosthodontics, \\ SPDC, Sawangi (M), Wardha, Maharashtra, India. ${ }^{3}$ Department of Prosthodontics, SPDC, Sawangi (M), Wardha, \\ Maharashtra, India. ${ }^{4}$ Department of Prosthodontics, SPDC, Sawangi (M), Wardha, Maharashtra, India. ${ }^{5}$ Department of \\ Prosthodontics, SPDC, Sawangi (M), Wardha, Maharashtra, India.
}

\section{ABSTRACT}

\section{BACKGROUND}

The restoration of endodontically treated teeth is a challenge as these teeth loose significant part of the tooth structure due to caries, previous restorative procedures, endodontic access cavity preparation or due to loss of moisture supplied by dentin, which makes them weak. The restoration of such teeth is accomplished by using post and core, to prevent further destruction and to provide retention for the core, before a crown or a fixed partial denture can be placed. Post-retained crowns are indicated for endodontically treated teeth (ETT) with severely damaged coronal tissue. There are still controversies for the most suitable choice of restorative material and the placement method that will result in the highest success rate. This clinical study compares the para post, fiber post and ceramic post in the restoration of the endodontically treated teeth. We wanted to evaluate and compare the retentive properties of three different post systems used for endodontically treated teeth for providing restoration.

\section{METHODS}

Sixty extracted human, single rooted, caries free, non-fractured tooth were selected and disinfected using $2 \%$ chlorhexidine solution and subsequently stored in distilled water. Each group consists of 20 samples. The crown structures of teeth were separated from root at cemento-enamel junction. Canal was obturated with gutta-percha and endodontic sealer. The posts were coated with Selfcem and also the resin cement was transported into the canal by the lentulospiral. A custom made two-piece stainless-steel mould was used for fabrication of standard size resin blocks in which teeth specimens were mounted. After the complete curing of autopolymerising acrylic resin, after 30-45 minutes, the block was retrieved from the mould The specimen with acrylic block was mounted on lower jaw of universal testing machine. The retentive strength was calculated as maximum tensile load that a sample can withstand post dislodgement.

\section{RESULTS}

Descriptive statistical analysis, one-way ANOVA, multiple comparison Tukey test were used. SPSS Ver. 16.0 was used for statistical analysis. Statistical analysis showed significant difference between the retentive strengths of all the three post systems $(\mathrm{p}<0.05)$. Group I: $259.17 \pm 27.37$, Group II: $153.83 \pm 29.16$, and group III: $118.40 \pm 12.95$. Paraposts showed highest retention followed by Fiberposts and then followed by Ceramic posts.

\section{CONCLUSIONS}

Prefabricated metal posts have the highest retention when compared with the other two post systems.

\section{KEY WORDS}

Post System, Cast Post, Fiber Post, Ceramic Post, Dual Core Resin

\author{
Corresponding Author: \\ Dr. Seema Sathe, \\ Department of Prosthodontics, \\ SPDC Sawangi (M), Wardha-442001, \\ Maharashtra, India. \\ E-mail: seemasathe2011@gmail.com
}

DOI: $10.14260 /$ jemds $/ 2019 / 813$

Financial or Other Competing Interests: None.

How to Cite This Article:

Ramteke S, Kambala S, Godbole S, et al. Comparative evaluation of the retentive qualities of three different post systems used for endodontically treated teeth for providing restoration- an in vitro study. J. Evolution Med. Dent. Sci. 2019;8(50): 3754-3758, DOI:
Submission 23-09-2019,

Peer Review 27-11-2019,

Acceptance 03-12-2019,

Published 16-12-2019. 


\section{BACKGROUND}

Teeth provide self-confidence, improve quality of life and allow us to have an overall sense of well-being. Sometimes, teeth may suffer damage often from a deep cavity or trauma and the pulp tissue inside the tooth may become inflamed or infected. In the permanent dentition, fractures comprise 26$76 \%$ of dental injuries. The most affected teeth are maxillary incisors due to their anterior position and protrusion caused by the erupting process. The healing of these fractures can be complicated because the wound in root fractures involves damage to all dental tissues, including the pulp, dentin, periodontal ligament, and cementum and is sometimes associated with damage to the supporting alveolar bone.Such conditions are treated either by extraction of that tooth or endodontic therapy for affected tooth. ${ }^{1}$ Post and cores are a commonly accepted method for restoring endodontically treated teeth and retention of a post and core is vital for longterm success of the final restoration. The restoration of endodontically treated teeth with post and core is a challenge. Clinical success depends on proper diagnosis, selection of teeth to be restored, the type of post and luting agent. Root fractures occur at the area where the tension stress is at the most critical values at the root of the tooth and they are influenced by the post type that is applied to the tooth. Adequate retention of the post is a pre- requisite for the success of post retained crown. The prime objectives of post and core procedure are to build missing coronal structure as well as to provide sufficient retention and resistance form to final restoration. In earlier days, custommade post and core restoration was one of the popular methods to restore endodontically treated teeth. Later on, prefabricated posts gained importance due to reduced time and feasibility. Post failures are either due to lack of strength of dowel itself or, more commonly, the lack of sufficient retention of the dowel in the root. ${ }^{2}$ The retentive failure of crowns supported by post has been reported. Restorations supported with cast post cores result in radicular fractures at teeth roots when they are compared with prefabricated posts. According to many studies, as for the fiber post application on teeth with canal treatment, it increases the fracture resistance of the teeth substantially by exposing better stress dispersion on roots of teeth. Eight factors have been identified to affect the retention of prefabricated posts. The variables reported to affect the retention include length, diameter, design of the post, canal shape and preparation, luting medium, method of cementation and location in the dental arch. ${ }^{3}$ Various luting agents include Zinc phosphate, polycarboxylate, glass ionomer and filled and unfilled resin cements have been used so far. The use of filled and unfilled resins as luting agents has increased. ${ }^{3}$ Currently, various prefabricated metal and non- metal posts are commercially available. Also, the trending luting agents that are available are the resin based luting agents. ${ }^{4}$

This study aimed to evaluate and compare the retentive strengths of three different post systems used in endodontically treated teeth for providing restoration.

\section{Objectives}

1. To evaluate retentive strength of cast post luted with dual cure resin cement in endodontically treated teeth.
2. To evaluate retentive strength of fiber post luted with dual cure resin cement in endodontically treated teeth.

3. To evaluate retentive strength glass fiber post luted with dual cure resin cement in endodontically treated teeth.

4. Comparative evaluation of retentive strengths.

\section{METHODS}

Sixty extracted human ${ }^{5}$, single rooted, caries free, nonfractured were selected and disinfected using $2 \%$ Chlorhexidine solution and subsequently stored in distilled water. Samples were divided into three groups-

\section{Group I}

20 samples with prefabricated metal posts, Parapost XP, Coltene, Whaledent, Inc luted with SelfCem.

\section{Group II}

20 samples with Fiber posts (Ammdent, India) luted with SelfCem.

\section{Group III}

20 samples with custom made Ceramic posts luted with SelfCem.

\section{Preparing Custom-Made Ceramic Posts}

The glass fiber posts that were used in this study were duplicated with the help of Polyvinylsiloxane impression material - putty consistency. A mould was created out of it and pattern wax was poured in it. The pattern that was obtained was invested and burned out. The IPS e.max Press ingot was heat pressed into the post mould. The ceramic post was retrieved. Finishing of the ceramic post was carried out. The crown structures of teeth were separated from root at cemento-enamel junction with diamond rotary bur, on a highspeed handpiece. The root canal was mechanically enlarged using sequential endodontic file from no.15 up to size of no.40. Canal was irrigated with distilled water. Canal was dried with paper points. Canal was obturated with guttapercha and endodontic sealer. Endodontic drill of size 2 was marked at $8 \mathrm{~mm}$ length from tip with permanent marker and rubber stopper was attached to the drill at marked position. The length of post space was decided by taking into consideration the study carried out by S-0 Hedlund 6 in 2003, in which he evaluated the retention of prefabricated posts in premolars.

The posts were coated with Selfcem and also the resin cement was transported into the canal by the lentulospiral. Posts of all the three groups were then luted in the prepared post space using Selfcem self-adhesive resin cement. A custom made two-piece stainless-steel mould was used for fabrication of standard size resin blocks in which teeth specimens were mounted. After confirming proper position of specimen and mould on surveyor, autopolymerising acrylic resin powder and liquid was mixed in thin consistency and poured around tooth specimen to fill the mould completely. After the complete curing of autopolymerising acrylic resin, after 30-45 minutes, the block was retrieved from the mould.? 
The specimen with acrylic block was mounted on lower jaw of universal testing machine. A custom-made pull-out fixture consisting of holding chuck $(1.5-10 \mathrm{~mm}$ SAN OU 0.5$20 \mathrm{UNF}$ ) and attached metal rod (length $-7 \mathrm{cms}$, and diameter $1 \mathrm{~cm}$ ) was secured to upper jaw of universal testing machine. The coronal extension of the posts was secured in custom-made pull-out fixture. The tensile load test/ pull out test was carried out at cross head speed of $0.5 \mathrm{~mm} / \mathrm{min}$ for all 60 specimens. The load applied was in Newton $(\mathrm{N})$ and the load was continued until the posts got dislodged from teeth samples. The retentive strength was calculated as maximum tensile load that a sample can withstand post dislodgement.

\section{Statistical Analysis}

Descriptive statistical analysis, one-way ANOVA and multiple comparison Tukey test were used. Data was analysed with SPSS Ver.16.0. The mean retentive values of all the post systems are summarized in table 1. Statistical analysis showed significant difference between the retentive strengths of all the three post systems $(\mathrm{p}<0.05)$. Group I: $259.17 \pm 27.37$, Group II: $153.83 \pm 29.16$, and group III: 118.40 \pm 12.95. Paraposts showed highest retention followed by Fiberposts and then followed by Ceramic posts.

\section{RESULTS}

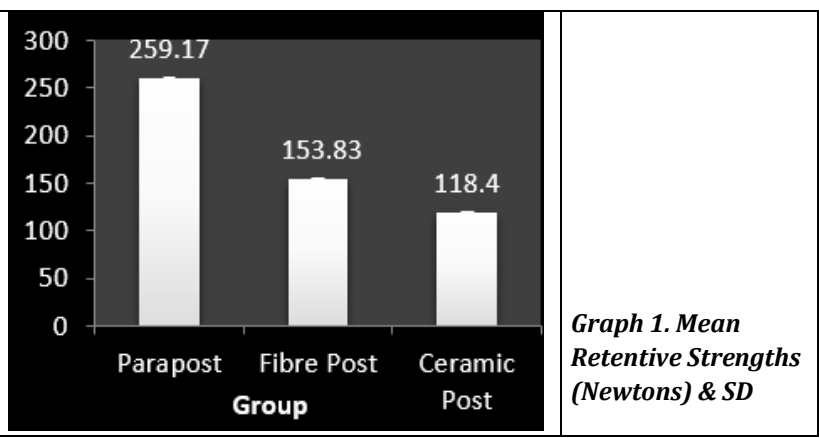

\begin{tabular}{|c|c|c|}
\hline & Mean & SD \\
\hline Group I & 259.17 & 27.37 \\
\hline Group II & 153.83 & 29.16 \\
\hline Group III & 118.40 & 12.95 \\
\hline \multicolumn{2}{|c|}{ Table 1. Mean Retentive Value of Post Systems } \\
\hline
\end{tabular}

\section{DISCUSSION}

The focus of dentistry in the present times is not only on the prevention and treatment but also on the demands for better esthetics and function of the restoration. The need for esthetically acceptable restoration with good dimensional stability, retention and color stability has increased nowadays. ${ }^{8}$ Endodontically treated teeth requiring artificial crowns should have a post and core system to increase the retention of the crown and to resist fracture of the tooth. The main purpose of the post and core restoration is to provide a substructure on which the final restoration can attach and anchor to the root. Therefore, the retention of the post to the root is of key importance. ${ }^{9}$
The failures related to various posts and core systems are grouped into three types- 1 . Debonding/loosening of post from root canal 2. Fracture of root 3. Cohesive fracture of post. Out of these, debonding is the most frequent type of failure and the fracture of root is the most serious type as it leads to the irreparable damage of tooth. Retention of the posts is claimed to be enhanced by a combination of surface treatment of the post, luting agent, type of technique used for luting, etc.

Selfcem was used because the self-adhesive resin cements do not require any pre-treatment of the tooth substrate i.e. once the cement is mixed, application is accomplished through a single clinical step. In this study, the lentulospiral technique was followed for cementing the posts. This technique of cementing a post is known to result in the least voids.

Gary R. Goldstein, Stephen I. Hudis, and Dale E. Weintraub, in 1986,11 in their study concluded that lentulospiral technique produced least voids. The other techniques are reported to produce voids in increasing numbers in the following order; the endodontic explorer, direct application, and the paper points.

After the samples were prepared, surveyor was used to embed the tooth/post complex in auto-polymerizing acrylic resin. This allowed the tensile force to be applied in an axial direction eliminating any diagonal vector forces.

The pull-out test was chosen, because the results that are so obtained of the shear force are comparable to clinical findings. The pull-out test is more suitable than the push-out test when the objective is to measure the holding force of the post along the duct (root canal) and it better distributes stress, and is considered accurate to measure the bond strength between the post and root dentin. Mariana Benedetti Ferreira Webber et al ${ }^{12}$ in their study have also used similar test.

The highest retentive strength shown by the Parapost can be attributed to the fact that parallel sided post is most retentive with least stress. This fact commensurates with the studies done by Standlee JP13 and associates who have reported that in tension, a parallel sided post is more retentive followed by the parallel-tapered combination design. This is because parallel posts resist tensile, shear, and torqueing forces better than tapered posts. ${ }^{14}$

Another reason for better retention of the Parapost system could be due tothe serrations on the post surface which lead to increased retention when compared with a smooth surface, as reported by Tilk, Lommel and Gerstein. ${ }^{3}$

Studies by Cooney JP and Ross RS have reported that a well-adapted, passively luted, parallel- sided post provides most retentive features with least stress ${ }^{3}$. Reumping DR, Standlee JP and Jerry $\mathrm{KJ}^{13,14,15}$ have indicated that the variables affecting post retention are shape, size of the retentive area, and surface roughness. And, studies by Leary JM and Colman HL have shown that the tapered post was the least retentive. ${ }^{3}$

Fiber posts have shown less retentive strength as compared to stainless steel posts in this study. Similar results were obtained by B.I. Cohen ${ }^{5}$ in which he evaluated the retention of two prefabricated post systems. The cause of this failure could be because the glass fiber post is made of an epoxy resin matrix, a highly cross-linked polymer without silicate, this makes it difficult to lute with composite resins and tooth structure as 
reported by Chang Liu, Hong Liu, Yue-Tong Quian, and Song Zhu. ${ }^{16}$ The lowest retentive strength of Ceramic post used in this study approximates with the Cosmoposts used in a study done by Anahita Safari, Amir Alireza Khaledi, Zeinab Shafiei and Naeeme Rahmani ${ }^{17}$ in 2014 , in which they evaluated the fracture resistance and retention of two all- ceramic post and core systems.

As Zirconia has reduced micromechanical retention with a detrimental effect on bond strength, this would explain the adhesive failure between the post and cement as opposed to cohesive failure within the cement or adhesive failure between the cement and root dentin. ${ }^{18}$

This is supported by the studies done by Kern and Wegner 18 in which they have shown lack of a long-term durable chemical bond between resin cements and Zirconia ceramics. Any cement used to lute such posts would rely on micromechanical retention.

Visual inspection of failed fiber posts and ceramic posts used in this study showed the lack of cement remnants on their surface. This clearly suggested adhesive failure at the cement/post interface. The presence of cement on paraposts were suggestive of adhesive and cohesive failure at the cement-post and within the cement respectively.

The high retention value of Parapost and the relatively low retention of Ceramic post is consistent with the observation in a similar study by Purton, Love and Chandler ${ }^{19}$ in which they have concluded that the serrated, parallel, stainless steel posts were significantly more retentive in roots than the smooth, tapering, ceramic posts.

However, as described by Assif and Bleicher, ${ }^{20}$ the diverse retention values within different post systems may be attributed to-

1. Cement composition that is not uniform for all the three posts.

2. Various quantities of dentin particles in the prepared canal after cleaning and in smear layers.

3. Absence of controls to ensure the identical position of all posts for uniform width of cement layer surrounding the posts.

4. Differences in the dentin of teeth resulting from moisture content, pulpal condition at the time of extraction, age of patient, and direction of dentinal tubules.

5. Inconsistent and unpredictable cementing pressure during the setting process.

Satheesh B. Haralur et al ${ }^{21}$ carried out a study to check resistance and concluded that the restoration of ETT with larger canals by multiple FRC and metal posts provides substantially higher fracture resistance in comparison to wider single post. The primary function of a corono-radicular post is to provide retention for a core, which replaces lost coronal tooth structure and retains the final restoration. Therefore, it is important to select a post system that provides maximum retention to the root canal as well as to the core.

\section{CONCLUSIONS}

Prefabricated metal posts have the highest retention when compared with the other two post systems. This is clinically more helpful if posterior endodontically treated teeth are to be restored. The glass fibre posts have an acceptable retentive strength and can be used in both anterior as well as posterior teeth. If aesthetic demands are high, then ceramic posts can be used in the anterior region where masticatory forces are comparatively less.

\section{REFERENCES}

[1] Fernandes A, Rodrigues S, Sardessai G, et al. Retention of endodontic post - a review. Journal of Endodontology 2001;13:11-18.

[2] Deutsch AS, Musikant BL, Cavallari J, et al. Prefabricated dowels: a literature review. Journal of Prosthetic Dentistry 1983;49(4):498-503.

[3] Stockton LW. Factors affecting retention of post systems: a literature review. Journal of Prosthetic Dentistry 1999;81(4):380-5.

[4] Duncan JP, Pameijer CH. Retention of parallel sided titanium posts cemented with six luting agents: an in vitro study. Journal of Prosthetic Dentistry 1998;80(4):423-8.

[5] Cohen BI, Pagnillo M, Musikant BL, et al. Comparison of retentive and photoelastic properties of two prefabricated endodontic post systems; J Oral Rehabil 1999;26(6):488-94.

[6] Hedlund SO, Johansson NG, Sjogren G. Retention of prefabricated and individually cast root canal posts invitro. British Dental Journal 2003;195(3):155-8.

[7] Anusavice KJ. Anusavice KJ, Phillip's Science of dental materials. $11^{\text {th }}$ edn. St. Louis: WB Saunders Co., 2003: p. 143-6.

[8] Sathe S, Karva S, Borle A, et al. Comparative evaluation of the effect of three polishing agents on staining characteristics of provisional restorative material: an in vitro study. J Int Soc Prevent Community Dent 2019;9(3):250-5.

[9] Cohen BI, Musikant BL, Deutsch AS. Comparison of retentive properties of four post systems. Journal of Prosthetic Dentistry 1992;68(2):264-8.

[10] Khoury CK, Zarazir R. Fiber posts: cementation techniques. Smile Dental Journal 2012;7(2):44-7.

[11] Goldstein GR, Hudis SI, Weintraub DE. Comparison of four techniques for cementation of posts. Journal of Prosthetic Dentistry 1986;55(2):209-11.

[12] Webber MBF, Michida SM, Marson FC, et al. Analysis of bond strength by pull out test on fiber glass posts cemented in different lengths. Journal of International Oral Health 2015;7(4):7-12.

[13] Standlee JP, Caputo AA, Hanson EC. Retention of endodontic dowels: effect of cement dowel strength, diameter and design. Journal of Prosthetic Dentistry 1978;39(4):400-5.

[14] Reumping DR, Lund MR, Schnell RJ. Retention of dowels subjected to tensile and torsional forces. Journal of Prosthetic Dentistry 1979;41(2):159-62.

[15] Johnson JK, Sakumura JS. Dowel form and tensile force. Journal of Prosthetic Dentistry 1978;40(6):645-9. 
[16] Liu C, Liu H, Quian YT, et al. The influence of four dualcured resin cements and surface treatment selection to bond strength of fiber post. International Journal of Oral Science 2014;6(1):56-60.

[17] Safari A, Khaledi AA, Shafiei Z, et al. The retention and fracture resistance of two all-ceramic post-and-core systems in anteriorly endodontically treated teeth. Galen Medical Journal 2014;3(2):95-101.

[18] Kern M, Wegner SM. Bonding to zirconia ceramic: adhesion methods and their durability. Dent Mater 1998;14(1):64-71.
[19] Purton DG, Love RM, Chandler NP. Rigidity and retention of ceramic root canal posts. Journal of Operative Dentistry 2000;25(3):223-7.

[20] Purton DG, Love RM. Rigidity and retention of carbon fibre versus stainless steel root canal posts. International Endodontic Journal 1996;29(4):262-5.

[21] Haralur SB, Al-Ahmari MA, Al-Qarni SA, et al. The effect of intraradicular multiple fiber and cast posts on the fracture resistance of endodontically treated teeth with wide root canals. Biomed Research International Journal 2018;2018:1671498. 